\title{
Evaluating the safety of early surgery for ruptured intracranial aneurysms in patients with long-term aspirin use: a propensity score matching study
}

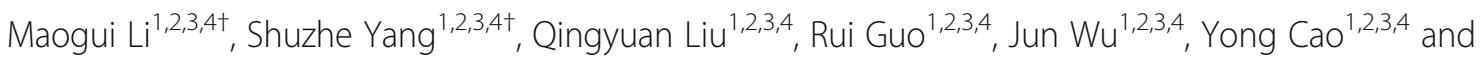
Shuo Wang ${ }^{1,2,3,4^{*}}$

\begin{abstract}
Background: Early microsurgical clipping is recommended for ruptured intracranial aneurysms to prevent rebleeding. However, dilemma frequently occurs when managing patients with current acetylsalicylic acid (aspirin) use. This study aimed to examine whether aspirin use was associated with worse outcomes after early surgery for aneurysmal subarachnoid hemorrhage (aSAH).
\end{abstract}

Methods: We retrieved a consecutive series of 215 patients undergoing early microsurgical clipping within $72 \mathrm{~h}$ after aneurysmal rupture from 2012 to 2018 in the neurosurgery department of Beijing Tiantan Hospital. The medical records of each case were reviewed. Twenty-one patients had a history of long-term aspirin use before the onset of aSAH, and 194 patients did not. To reduce confounding bias, propensity score matching (PSM) was performed to balance some characteristics of the two groups. The intraoperative blood loss, postoperative hemorrhagic events, postoperative hospital stay, and functional outcome at discharge were compared between aspirin and non-aspirin group.

Results: We matched all the 21 patients in aspirin group with 42 patients in non-aspirin group (1:2). Potential confounding factors were corrected between the two groups by PSM. No hospital mortality occurred after surgery. No significant differences were found in intraoperative blood loss $(P=0.540)$, postoperative hemorrhagic events $(P>0.999)$, postoperative hospital stay $(P=0.715)$, as well as functional outcome at discharge $(P=0.332)$ between the two groups.

Conclusions: Our preliminary results showed that long-term low-dose aspirin use was not associated with worse outcomes. Early surgery can be safe for ruptured intracranial aneurysms in patients with long-term aspirin use.

Keywords: Intracranial aneurysm, Subarachnoid hemorrhage, Early surgery, Aspirin, Antiplatelet

\footnotetext{
* Correspondence: captain9858@126.com

${ }^{+}$Maogui Li and Shuzhe Yang contributed equally to this work.

'Department of Neurosurgery, Beijing Tiantan Hospital, Capital Medical

University, 119 South Fourth Ring Road West, Fengtai District, Beijing 100070,

China

${ }^{2}$ China National Clinical Research Center for Neurological Diseases, Beijing,

China

Full list of author information is available at the end of the article
}

C The Author(s). 2020 Open Access This article is licensed under a Creative Commons Attribution 4.0 International License, which permits use, sharing, adaptation, distribution and reproduction in any medium or format, as long as you give appropriate credit to the original author(s) and the source, provide a link to the Creative Commons licence, and indicate if changes were made. The images or other third party material in this article are included in the article's Creative Commons licence, unless indicated otherwise in a credit line to the material. If material is not included in the article's Creative Commons licence and your intended use is not permitted by statutory regulation or exceeds the permitted use, you will need to obtain permission directly from the copyright holder. To view a copy of this licence, visit http://creativecommons.org/licenses/by/4.0/. The Creative Commons Public Domain Dedication waiver (http://creativecommons.org/publicdomain/zero/1.0/) applies to the data made available in this article, unless otherwise stated in a credit line to the data. 


\section{Background}

Acetylsalicylic acid (aspirin) is the most widely used antiplatelet drug in primary prevention and secondary prevention of atherosclerosis diseases [1]. Chronic use of low-dose aspirin can significantly inhibit platelet aggregation. Past researches have studied the effects of preoperative aspirin use on bleeding risk of noncardiac surgeries. Large studies reported an increased risk of bleeding complications in patients with continuation of preoperative aspirin undergoing noncardiac surgeries [24], while some studies believed that perioperative discontinuation of aspirin raised the risk of cardiovascular accident without lowering bleeding risk $[5,6]$. However, these studies seldom included patients undergoing craniotomy operations. Because of the serious consequences of intracranial hemorrhage, many surgeons suggested aspirin therapy be stopped for more than 7 days before elective neurosurgery to avoid the increased bleeding risk $[7,8]$. However, this option does not apply to emergency situation. Aneurysm rebleeding is associated with significant mortality and poor outcomes after intracranial aneurysmal subarachnoid hemorrhage (aSAH) [9]. Thus, the recommended timing to repair ruptured aneurysms has become early within $72 \mathrm{~h}$ after the onset of aSAH [10-12]. However, dilemma frequently occurs when managing patients with current aspirin use. The association between aspirin use and postoperative outcomes in aSAH patients undergoing early surgery remains unclear. A recent traumatic neurosurgical study found that low-dose aspirin use without preoperative cessation was not associated with unfavorable outcomes after emergency surgery for traumatic intracranial hemorrhage [13]. Further evidence on the safety of early surgery in aSAH patients with long-term aspirin use is needed.

In this study, we reviewed a consecutive series of patients with and without aspirin use who underwent early microsurgical clipping for aSAH. We compared perioperative bleeding events and postoperative outcomes between aspirin and non-aspirin group, aiming to examine whether aspirin use was associated with worse outcomes after early surgery for ruptured aneurysms.

\section{Methods}

\section{Patient selection}

This retrospective study was approved by the Institutional Review Board. The procedures followed were in accordance with the ethical standards with the Helsinki Declaration. Between 2012 and 2018, a total of 215 patients underwent early microsurgery after intracranial aneurysm rupture in our institution. We included the patients with the following inclusion criteria: (1) SAH confirmed by plain computed tomography (CT), with responsible aneurysms detected by CT angiography (CTA) or digital subtraction angiography (DSA), (2) treated by microsurgical clipping within $72 \mathrm{~h}$ after aSAH onset. The exclusion criteria used were (1) non-aneurysmal subarachnoid hemorrhage, (2) multiple aneurysms treated simultaneously, (3) undergoing operation other than direct clipping (e.g., wrapping or trapping), (4) currently using clopidogrel, warfarin, and other antithrombotic drugs before surgery.

In our institution, aSAH patients with Hunt-Hess $(\mathrm{HH})$ grade $\leq 3$ are commonly treated early. Aneurysms located in internal carotid artery or posterior circulation are firstly treated by endovascular treatment, while distal aneurysms, aneurysms not suitable for coiling, and aSAH combined with large hematoma or brain hernia are considered to be treated by microsurgery. The preference of patient or family influenced treatment decision as well.

\section{Data collection}

Demographic, aneurysm, and clinical data were retrospectively collected from our electronic medical database. Patient characteristics included sex, age, the dosage of preoperative aspirin use, and any history of the following comorbidities: cardio-cerebrovascular accident, hypertension, or diabetes mellitus. Aneurysm characteristics included size and site. The maximum diameter of aneurysm was measured on preoperative threedimensional CTA or DSA. The site was roughly divided into anterior circulation and posterior circulation aneurysms. Clinical data collected included admission $\mathrm{HH}$ grade, modified CT Fisher grade [14], intraoperative blood loss, postoperative hemorrhage events, and neurological function at discharge. The HH grade and modified Fisher scale were assessed by two experienced investigators based on preoperative clinical condition and brain CT scan. The $\mathrm{HH}$ grade was divided into two groups: grades 1 to 3 and grades $4-5$. The modified Fisher grade was classified as grade 1 , grades $2-3$, and grade 4 [14]. The history of taking antiplatelet drugs was recorded. Patients were divided into aspirin group and non-aspirin group according to whether they received chronic aspirin therapy or not.

\section{Outcome assessment}

The outcomes assessed in this study were as follows: (1) intraoperative blood loss, (2) postoperative hemorrhagic events, (3) postoperative infarction, (4) hospital mortality, (5) length of postoperative hospital stay, and (6) functional outcome at discharge.

Intraoperative blood loss was collected from the anesthesia record. Postoperative hemorrhagic events included intracranial and gastrointestinal bleeding. Intracranial hemorrhage or cerebral infarction was confirmed by postoperative CT scan. Hemorrhage from aneurysm intraoperative rupture or postoperative rebleeding caused by unsuccessful clipping was excluded. Neurological function was evaluated 
with the modified Rankin Scale (mRS). Functional impairments clearly associated with other comorbidities were not ascribed to surgery. An mRS score $\geq 3$ meant an unfavorable outcome.

\section{Statistical analysis}

We performed statistical analysis by using SPSS 22.0 (SPSS Inc., Chicago, IL, USA). Continuous variables are presented as mean \pm standard deviation (SD) and categorical variables as number (\%). To minimize confounding bias associated with nonrandomized retrospective design, we did propensity score matching (PSM) to balance the baseline characteristics of the aspirin and non-aspirin group. The propensity score of each patient was estimated with logistic regression model. The following potential confounding factors were used as covariates: sex, age, comorbidity history, admission $\mathrm{HH}$ grade, CT modified Fisher grade, aneurysm size, and site. The matching rate was $1: 2$ for the aspirin group to non-aspirin group, and the caliper width was set at 0.2 . The nearest neighbor method was used. To test the calibration effectiveness of the PSM, the baseline characteristics were compared between the aspirin and non-aspirin group before and after the 1:2 matching. Then, we compared the outcomes between the two matched groups. We used Chi-square test to compare categorical variables. Continuous variables were compared by Mann-Whitney $U$ test. The level of significance was set at $P<0.05$, and all tests were 2 -sided.

\section{Results}

Demographics and clinical characteristics

After data cleansing, 215 patients undergoing early microsurgery for ruptured intracranial aneurysms were reviewed. Among them, 21 patients were classified into aspirin group and 194 into non-aspirin group, according to preoperative aspirin use. The mean interval from onset to surgery was $2.5 \pm 0.6$ days. Twenty patients in the aspirin group received $100 \mathrm{mg}$ aspirin per day, and $1 \mathrm{pa}-$ tient had a dosage of $75 \mathrm{mg}$ per day. Aspirin was stopped immediately after aSAH onset. The baseline characteristics of the two groups are showed in Table 1. Because of the objective selection bias, patients in the aspirin group had an older mean age $(P=0.037)$ as well as a higher rate of past comorbidity history $(P=0.001)$, compared with those in the non-aspirin group. After the 1:2 PSM, 42 matched patients were extracted from the nonaspirin group. The aspirin group consisted of 14 females and 7 males with a mean age of $58.9 \pm 8.4$ years. The mean aneurysm size was $6.3 \pm 2.6 \mathrm{~mm}$, and the mean admission modified CT fisher grade was $3.2 \pm 1.1$. The non-aspirin group consisted of 32 females and 10 males with a mean age of $57.2 \pm 10.3$ years. The mean aneurysm size was $6.5 \pm 3.2 \mathrm{~mm}$, and the mean admission modified CT fisher grade was $3.2 \pm 1.0$. Comparison between these two matched groups showed no significant difference in demographic, aneurysm, and clinical baseline characteristics (Table 1).

Table 1 Characteristics of patients with and without long-term aspirin use before and after matching

\begin{tabular}{|c|c|c|c|c|c|c|}
\hline \multirow[t]{2}{*}{ Characteristics } & \multicolumn{3}{|c|}{ Before matching } & \multicolumn{3}{|l|}{ After matching } \\
\hline & $\begin{array}{l}\text { Aspirin group } \\
(n=21)\end{array}$ & $\begin{array}{l}\text { Non-aspirin group } \\
(n=194)\end{array}$ & $P$ value & $\begin{array}{l}\text { Aspirin group } \\
(n=21)\end{array}$ & $\begin{array}{l}\text { Non-aspirin group } \\
(n=42)\end{array}$ & $P$ value \\
\hline Age (year) & $58.9 \pm 8.4$ & $53.9 \pm 10.4$ & 0.037 & $58.9 \pm 8.4$ & $57.2 \pm 10.3$ & 0.737 \\
\hline Sex & & & 0.666 & & & 0.422 \\
\hline Male & $7(33.3)$ & $74(38.1)$ & & $7(33.3)$ & $10(23.8)$ & \\
\hline Female & $14(66.7)$ & $120(61.9)$ & & $14(66.7)$ & $32(76.2)$ & \\
\hline Hunt-Hess grade & & & $>0.999$ & & & $>0.999$ \\
\hline $1-3$ & $20(95.2)$ & $186(95.9)$ & & $20(95.2)$ & $40(95.2)$ & \\
\hline $4-5$ & $1(4.8)$ & $8(4.1)$ & & $1(4.8)$ & $2(4.8)$ & \\
\hline Modified Fisher grade & & & 0.331 & & & 0.285 \\
\hline 1 & $3(14.3)$ & $13(6.7)$ & & $3(14.3)$ & $2(4.8)$ & \\
\hline $2-3$ & $5(23.8)$ & $68(35.1)$ & & $5(23.8)$ & $16(38.1)$ & \\
\hline 4 & $13(61.9)$ & $113(58.2)$ & & $13(61.9)$ & $24(57.1)$ & \\
\hline Aneurysm size (mm) & $6.3 \pm 2.6$ & $6.2 \pm 3.3$ & 0.421 & $6.3 \pm 2.6$ & $6.5 \pm 3.2$ & 0.901 \\
\hline Site & & & $>0.999$ & & & $>0.999$ \\
\hline Anterior circulation & $21(100)$ & $191(98.5)$ & & $21(100)$ & $42(100)$ & \\
\hline Posterior circulation & 0 & $3(1.5)$ & & 0 & 0 & \\
\hline Comorbidity history & $20(95.2)$ & $113(58.2)$ & 0.001 & $20(95.2)$ & $42(100)$ & 0.333 \\
\hline Mean propensity score & 0.173 & 0.090 & & 0.165 & 0.163 & \\
\hline
\end{tabular}

Categorical variables are presented as number (\%), and continuous variables are presented as mean \pm standard deviation 


\section{Treatment outcomes}

None of the 63 patients received blood product transfusion before surgery. Table 2 summarizes the treatment outcomes of the two matched groups. The mean intraoperative blood loss of the aspirin group was $257.1 \pm$ $119.7 \mathrm{ml}$, while that of the non-aspirin group was 296.4 $\pm 280 \mathrm{ml}$ with no significant difference $(P=0.540)$. In regard to postoperative complications, the rate of hemorrhagic events in the aspirin group (19.0\%) was higher than that in the non-aspirin group (16.7\%), but this did not reach statistical significance $(P>0.999)$. Figure 1 compares the rate of patients according to intraoperative blood loss and the incidence of postoperative hemorrhagic events between the two groups. Postoperative cerebral infarction occurred in 6 patients in the aspirin group with the rate of $28.6 \%$, which is similar with that $(31.0 \%)$ in the non-aspirin group $(P=0.846)$. No patient died during hospitalization. The mean length of postoperative hospital stay was $14.0 \pm 5.4$ and $14.5 \pm$ 5.6 days respectively in the two groups. In regard to the functional status at discharge, favorable outcome was obtained in 13 of 21 (61.9\%) patients in the aspirin group, compared with 31 of $42(73.8 \%)$ patients in the non-aspirin group. However, this did not reach statistical significance $(P=0.332)$.

\section{Discussion}

Low-dose aspirin has been used to prevent cardiocerebrovascular diseases by a wide range of population [1], including some emergency aSAH patients. In the consecutive series of this study, $9.8 \%$ of patients were taking long-term aspirin before the onset of aSAH. This incidence is consistent with the rate of 9.5 to $11.7 \%$ reported in past studies $[15,16]$. The influence of prehemorrhage aspirin use on the presenting severity has been examined. Gross et al. [16] found that neither $\mathrm{HH}$ grade nor Fisher grade was associated with aspirin use. Dasenbrock et al. [17] even reported a better NIS-SAH severity score in patients taking aspirin. In the present study, we did not observe significant differences in aSAH presenting severity between patients with and without aspirin use, which coincided with the former research. Notably, Toussaint et al. [15] reported increased rebleeding rates in aspirin users, which could be explained by the antiplatelet effect of aspirin.

Rebleeding is the common cause of significantly poor outcome after aSAH, which can occur until definite treatment of ruptured aneurysms. During the past decades, early treatment within $72 \mathrm{~h}$ after onset of aSAH has been recommended to improve outcomes. However, because of the increased bleeding risk associated with antiplatelet agents, the safety of early surgery for aSAH patients receiving aspirin has been overshadowed. In this study, we evaluated the relationships between preoperative aspirin use and outcomes after early microsurgical clipping. Although patients with aspirin use were significantly older and had a greater rate of comorbidities than those without, after propensity score matching, we found no differences in intraoperative blood loss, postoperative hemorrhagic events, cerebral infarction, length of hospital stay, as well as unfavorable functional outcome between the aspirin group and non-aspirin group. These results suggested that long-term low-dose aspirin use was not associated with adverse outcomes after early surgery of aSAH. This is in agreement with the findings of a recent traumatic neurosurgical study. In that retrospective study involving 171 patients (87 receiving preoperative aspirin), they concluded that low-dose aspirin use without preoperative cessation was not associated with unfavorable outcomes after emergency surgery for traumatic intracranial hemorrhage [13].

Nevertheless, published literatures did not reach a consensus on the relationships between aspirin use and neurosurgical outcomes. In another traumatic study with small sample size, a decreased mortality was noted in aspirin users with traumatic subdural hematoma [18]. By contrast, Li et al. [19] examined the effect of preoperative aspirin use on outcomes of patients with spontaneous intracranial hemorrhage undergoing craniotomy, finding significantly increased rates of intraoperative blood loss, postoperative hemorrhage, and mortality in aspirin users compared with non-users. Few literatures

Table 2 Comparison of postoperative outcomes between aspirin and non-aspirin group

\begin{tabular}{llll}
\hline Outcomes & Aspirin group $(\boldsymbol{n}=\mathbf{2 1})$ & Non-aspirin group $(\boldsymbol{n}=\mathbf{4 2})$ & $\boldsymbol{P}$ value \\
\hline Intraoperative blood loss $(\mathrm{ml})$ & $257.1 \pm 119.7$ & $296.4 \pm 280.8$ & 0.540 \\
Postoperative hemorrhagic events & $4(19.0)$ & $7(16.7)$ & $>0.999$ \\
Postoperative cerebral infarction & $6(28.6)$ & $13(31.0)$ & 0.846 \\
Postoperative hospital stay (days) & $14.0 \pm 5.4$ & $14.5 \pm 5.6$ & 0.715 \\
Functional outcome & & $31(73.8)$ & 0.332 \\
$\quad \mathrm{mRS}<3$ & $13(61.9)$ & $11(26.2)$ & \\
$\mathrm{mRS} \geq 3$ & $8(38.1)$ & & \\
\hline
\end{tabular}

Categorical variables are presented as number (\%), and continuous variables are presented as mean \pm standard deviation 


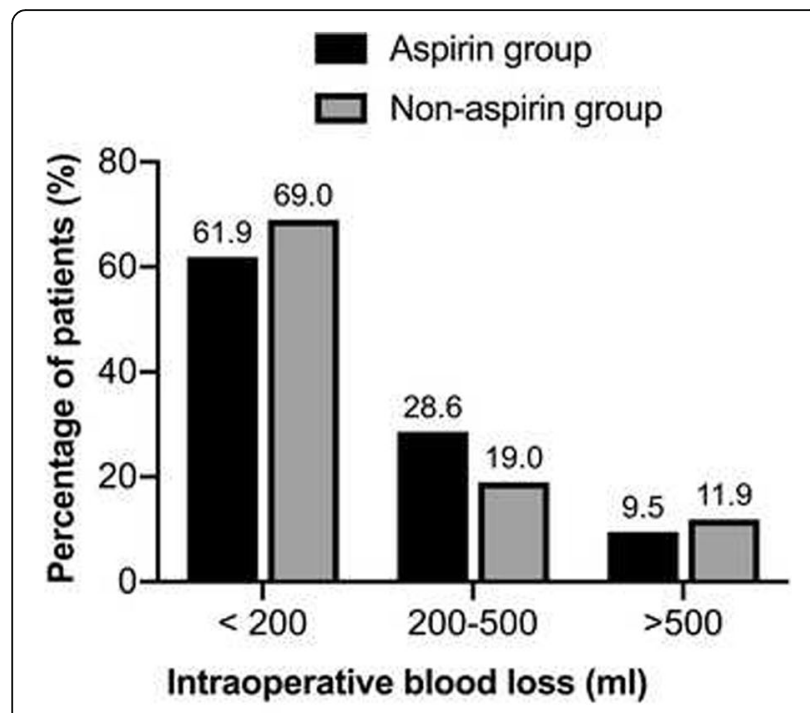

(a)

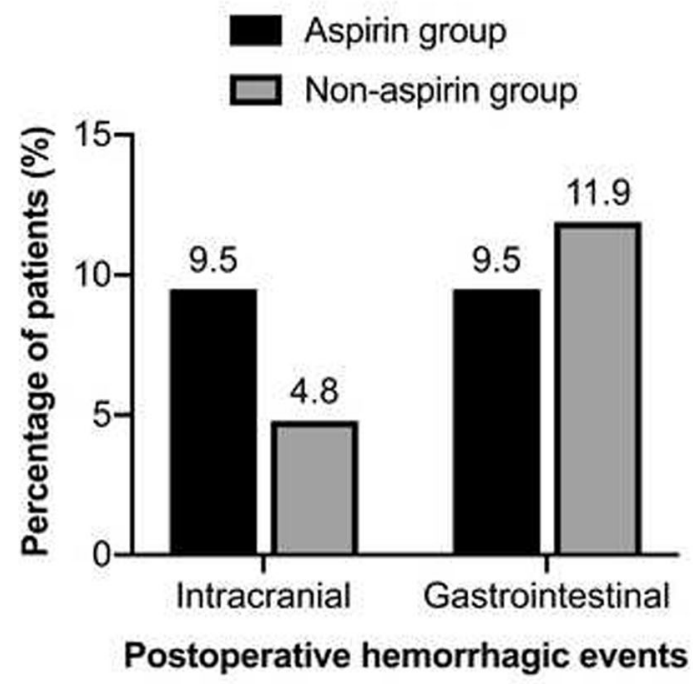

(b)

Fig. 1 Bleeding events associated with the aspirin group and nonaspirin group: the rate of patients according to intraoperative blood loss (a), and the incidence of postoperative hemorrhagic events (b)

have focused on the association between aspirin use and postoperative outcomes in aSAH patients undergoing microsurgical clipping. Dasenbrock et al. [17] found that neither hospital mortality nor total complication rates was associated with long-term aspirin use in aSAH patients treated surgically, but they did not note the time interval to surgery or whether aspirin was discontinued preoperatively.

In the present study, we evaluated the safety of early surgery with preoperative interval less than 3 days in aSAH patients with long-term aspirin use, finding no greater risks was associated with these patients. Aneurysm clipping is an "out of brain" operation, of which microsurgical maneuvers are commonly done in subarachnoid space rather than parenchyma. The possibility of intraoperative or postoperative tissue wound bleeding was much lower, compared with traumatic or spontaneous intracranial hemorrhage. The serious danger of aSAH surgery mainly comes from intraoperative aneurysm rebleeding. Thus, the safety of aSAH for aspirin users could be theoretically explained. We suggest early surgery for aSAH patients despite taking long-term aspirin mainly to eliminate the rebleeding risk. Besides, early surgery means a shorter duration of aspirin discontinuation, which can bring potential benefits. Previous research revealed that preoperative withdrawal of aspirin could significantly increase thrombotic risks, especially for patients with artery stents [3, 20]. In our series, 14 patients of the aspirin group had history of cardio-cerebrovascular accidents. In our institution, for patients with long-term aspirin use, antiplatelet is suggested to be early restarted after $24 \mathrm{~h}$ postoperatively if no hemorrhagic events occur.

Platelet transfusion has been recommended as a direct method to reverse the antiplatelet effect of aspirin in patients with intracranial hemorrhage who will undergo neurosurgery [21]. Li et al. [19] found significantly improved outcomes after intracranial hematoma evacuation in patients with aspirin use who received preoperative platelet transfusion. Controversially, evidence against platelet transfusion was reported by the PATCH trial [22]. Although in the present study positive outcomes were obtained in patients of the aspirin group without preoperative platelet transfusion, in our opinion, reversal of aspirin should be considered when platelet function is severely inhibited or aSAH is complicated with large hematoma.

\section{Limitation}

This study has some limitations. First, this is a small retrospective cohort study with selection bias. Although confounding factors have been corrected by the propensity score matching design, prospective controlled studies with sufficient population are needed to provide conclusive evidence. Second, data of platelet function testing or thromboelastography was lacking. Possible aspirin resistance might interfere with the results. Third, aSAH patients undergoing endovascular treatment were not studied in the present work. Despite these limitations, this study is the first to evaluate the safety of early surgery for ruptured intracranial aneurysms in patients with long-term aspirin use, providing preliminary evidence for decision-making. 


\section{Conclusions}

Our preliminary results showed that long-term low-dose aspirin use was not associated with increased intraoperative blood loss, postoperative hemorrhagic events, length of hospital stay, as well as unfavorable functional outcome. Early surgery can be safe for ruptured intracranial aneurysms in patients with long-term aspirin use.

\author{
Abbreviations \\ aSAH: Aneurysmal subarachnoid hemorrhage; PSM: Propensity score \\ matching
}

\section{Acknowledgements \\ Not applicable}

\section{Authors' contributions}

SW was in charge of supervising the whole study. ML and JW contributed to the conception or design of the work. ML and SY were responsible for drafting and revising. $\mathrm{RG}, \mathrm{QL}$, and SY contributed to data collection. SY and YC were responsible for analysis and interpretation of data. All authors contributed to manuscript revision, read, and approved the submission.

\section{Funding}

This work was supported by the National Key Research and Development Program of China (Grant No. 2016YFC1301800, S.W.) and the National Natural Science Foundation of China (Grant No. 81671129, S.W.).

\section{Availability of data and materials}

Please contact author for data request.

\section{Ethics approval and consent to participate}

This study was approved by the institutional review board of the Beijing Tiantan hospital (Ethical No. KY2017-076-01). The privacy of patients was effectively protected.

\section{Consent for publication}

Not applicable.

\section{Competing interests}

The authors declare that they have no competing interests.

\section{Author details}

${ }^{1}$ Department of Neurosurgery, Beijing Tiantan Hospital, Capital Medical University, 119 South Fourth Ring Road West, Fengtai District, Beijing 100070, China. ${ }^{2}$ China National Clinical Research Center for Neurological Diseases, Beijing, China. ${ }^{3}$ Center of Stroke, Beijing Institute for Brain Disorders, Beijing, China. ${ }^{4}$ Beijing Key Laboratory of Translational Medicine for Cerebrovascular Diseases, Beijing, China.

Received: 27 August 2020 Accepted: 6 November 2020 Published online: 30 November 2020

\section{References}

1. Antithrombotic Trialists C, Baigent C, Blackwell L, Collins R, Emberson J, Godwin J, et al. Aspirin in the primary and secondary prevention of vascular disease: collaborative meta-analysis of individual participant data from randomised trials. Lancet. 2009:373(9678):1849-60.

2. McQuaid KR, Laine L. Systematic review and meta-analysis of adverse events of low-dose aspirin and clopidogrel in randomized controlled trials. Am J Med. 2006;119(8):624-38.

3. Burger W, Chemnitius JM, KneissI GD, Rucker G. Low-dose aspirin for secondary cardiovascular prevention - cardiovascular risks after its perioperative withdrawal versus bleeding risks with its continuation - review and meta-analysis. J Intern Med. 2005;257(5):399-414.

4. Devereaux PJ, Mrkobrada M, Sessler DI, Leslie K, Alonso-Coello P, Kurz A, et al. Aspirin in patients undergoing noncardiac surgery. N Engl J Med. 2014;370(16):1494-503.

5. Mangano DT. Multicenter Study of Perioperative Ischemia Research G. Aspirin and mortality from coronary bypass surgery. N Engl J Med. 2002;347(17):1309-17.
6. Oscarsson A, Gupta A, Fredrikson M, Jarhult J, Nystrom M, Pettersson E, et al. To continue or discontinue aspirin in the perioperative period: a randomized, controlled clinical trial. Br J Anaesth. 2010;104(3):305-12.

7. James DN, Fernandes JR, Calder I, Smith M. Low-dose aspirin and intracranial surgery. A survey of the opinions of consultant neuroanaesthetists in the UK. Anaesthesia. 1997:52(2):169-72.

8. Korinth MC. Low-dose aspirin before intracranial surgery--results of a survey among neurosurgeons in Germany. Acta Neurochir (Wien). 2006;148(11): 1189-96 discussion 96.

9. Abraham MK, Chang WW. Subarachnoid hemorrhage. Emerg Med Clin North Am. 2016;34(4):901-16.

10. Steiner $T$, Juvela $S$, Unterberg A, Jung C, Forsting $M$, Rinkel $G$, et al. European Stroke Organization guidelines for the management of intracranial aneurysms and subarachnoid haemorrhage. Cerebrovasc Dis. 2013;35(2):93-112.

11. Connolly ES Jr, Rabinstein AA, Carhuapoma JR, Derdeyn CP, Dion J, Higashida RT, et al. Guidelines for the management of aneurysmal subarachnoid hemorrhage: a guideline for healthcare professionals from the American Heart Association/American Stroke Association. Stroke. 2012;43(6):1711-37.

12. Dorhout Mees SM, Molyneux AJ, Kerr RS, Algra A, Rinkel GJ. Timing of aneurysm treatment after subarachnoid hemorrhage: relationship with delayed cerebral ischemia and poor outcome. Stroke. 2012;43(8):2126-9.

13. Lee AT, Gagnidze A, Pan SR, Sookplung P, Nair B, Newman SF, et al. Preoperative low-dose aspirin exposure and outcomes after emergency neurosurgery for traumatic intracranial hemorrhage in elderly patients. Anesth Analg. 2017;125(2):514-20.

14. Claassen J, Bernardini GL, Kreiter K, Bates J, Du YE, Copeland D, et al. Effect of cisternal and ventricular blood on risk of delayed cerebral ischemia after subarachnoid hemorrhage: the Fisher scale revisited. Stroke. 2001;32(9):2012-20.

15. Toussaint LG 3rd, Friedman JA, Wijdicks EF, Piepgras DG, Pichelmann MA, Mclver Jl, et al. Influence of aspirin on outcome following aneurysmal subarachnoid hemorrhage. J Neurosurg. 2004;101(6):921-5.

16. Gross BA, Rosalind Lai PM, Frerichs KU, Du R. Aspirin and aneurysmal subarachnoid hemorrhage. World Neurosurg. 2014;82(6):1127-30.

17. Dasenbrock HH, Yan SC, Gross BA, Guttieres D, Gormley WB, Frerichs KU, et al. The impact of aspirin and anticoagulant usage on outcomes after aneurysmal subarachnoid hemorrhage: a Nationwide Inpatient Sample analysis. J Neurosurg. 2017;126(2):537-47.

18. Walcott BP, Khanna A, Kwon CS, Phillips HW, Nahed BV, Coumans JV. Time interval to surgery and outcomes following the surgical treatment of acute traumatic subdural hematoma. J Clin Neurosci. 2014;21(12):2107-11.

19. Li X, Sun Z, Zhao W, Zhang J, Chen J, Li Y, et al. Effect of acetylsalicylic acid usage and platelet transfusion on postoperative hemorrhage and activities of daily living in patients with acute intracerebral hemorrhage. J Neurosurg. 2013;118(1):94-103.

20. Gerstein NS, Schulman PM, Gerstein WH, Petersen TR, Tawil I. Should more patients continue aspirin therapy perioperatively?: clinical impact of aspirin withdrawal syndrome. Ann Surg. 2012;255(5):811-9.

21. Frontera JA, Lewin JJ 3rd, Rabinstein AA, Aisiku IP, Alexandrov AW, Cook AM, et al. Guideline for reversal of antithrombotics in intracranial hemorrhage: executive summary. A Statement for Healthcare Professionals From the Neurocritical Care Society and the Society of Critical Care Medicine. Crit Care Med. 2016:44(12):2251-7.

22. Baharoglu MI, Cordonnier C, Salman RA, de Gans K, Koopman MM, Brand A, et al. Platelet transfusion versus standard care after acute stroke due to spontaneous cerebral haemorrhage associated with antiplatelet therapy (PATC H): a randomised, open-label, phase 3 trial. Lancet. 2016;387(10038):2605-13.

\section{Ready to submit your research? Choose BMC and benefit from:}

- fast, convenient online submission

- thorough peer review by experienced researchers in your field

- rapid publication on acceptance

- support for research data, including large and complex data types

- gold Open Access which fosters wider collaboration and increased citations

- maximum visibility for your research: over $100 \mathrm{M}$ website views per year

At BMC, research is always in progress.

Learn more biomedcentral.com/submissions 